\title{
EDITORIAL
}

\section{LA U.D.C.A CONTINÚA CON SU PROCESO DE ACREDITACIÓN INSTITUCIONAL}

\author{
Germán Anzola Montero \\ Rector
}

La U.D.C.A, como miembro y partícipe de la estructura general de la Educación Colombiana y comprometida con los aspectos ambientales, ha sabido entender esta dinámica y promueve, como base de su desarrollo, la calidad en sus programas, cumpliendo los criterios básicos de la misma y, aún más, buscando ser distinguida por sus procesos formativos. Ha adoptado los criterios de Acreditación en alta calidad, como la fórmula para la formación de profesionales, que aporten a su propio desarrollo y contexto nacional o regional, de manera significativa, labor que continuará con el reconocimiento institucional, en general.

Es parte de la cultura institucional de la U.D.C.A mantener y continuar con el ejercicio reflexivo de autoevaluación, como instrumento y alternativa para el desarrollo, el mejoramiento y el crecimiento en la calidad educativa, con el fin de ofrecer a la sociedad colombiana, una alternativa de experiencia académica, desde nuestro deber ser; sin embargo, este ejercicio debe considerar las tendencias y propuestas actuales, de quienes son los administradores y gestores de la nueva política educativa en nuestro país. Consideraciones que, si bien no van en contravía de nuestro ejercicio, sí pueden generar impactos o limitaciones a las propuestas o iniciativas que se lleguen a contemplar y que son derivadas del ejercicio de autoevaluación y de autorregulación institucional.

Significa esto, que se debe desarrollar un ejercicio, que permita la sinergia entre los diferentes actores internos y externos de la Institución, con el fin de integrar los parámetros normativos y de evaluación externa de la calidad, con las capacidades institucionales, de tal forma que se pueda seguir un desarrollo, mejoramiento y crecimiento armónico, sin recaer en controversias, con los entes reguladores.

Lo mencionado expresa el deseo de la U.D.C.A por seguir trabajando en la obtención de la Acreditación de Alta Calidad, donde el punto de partida para el Concejo Nacional de Acreditación -CNA-, en un nuevo proceso, serán las recomendaciones manifiestas por dicha entidad, durante el proceso desarrollado en 2015-2016, así como otros aspectos de evolución de cada uno de los diferentes factores. Para ello, se requiere que los parámetros y las recomendaciones que se han obtenido, se enfoquen en el concepto de calidad, consolidando así, el plan de mejoramiento, para satisfacer las recomendaciones y las sugerencias que, al mismo tiempo, con hechos evidenciables, demuestren mejoras consecuentes y aportantes en lo pertinente, al Plan de Desarrollo Institucional 2015-2019, el cual, se soporta con la nueva estructura organizacional y gestión por procesos.

Por lo anterior, consideramos que no solo se debe ajustar lo circunstancial, evidenciado como debilidad, sino que los aspectos distintivos de las funciones sustantivas se desarrollen, de tal forma, que puedan mostrar mayores resultados de impacto, de divulgación y de alcance, para el cumplimiento de nuestra misión.

Esta es la razón, por la cual, nuestra planta docente se viene consolidando como un cuerpo cada vez más cualificado, que cuenta con soportes para la construcción de los nuevos profesionales integrales, con mejores capacidades para el desarrollo y orientación de actividades investigativas.

Para el fortalecimiento de las actividades de investigación, en el último periodo, se ha consolidado el escalafón docente, con 11 profesores con formación doctoral e iniciaron estudios doctorales otros cuatro profesores, a quienes hemos incorporado, mediante el convenio con la Fundación Instituto de Inmunología de Colombia -FIDIC-. Asimismo, este año no hemos ahorrado esfuerzos para reforzar otras actividades conducentes a consolidar la investigación, como es lograr el ascenso de diferentes grupos de investigación a mejores categorías, incrementando las publicaciones científicas, la publicación de libros y realizando significativos esfuerzos para obtener patentes y registros, como producto de las actividades científicas.

Consecuentes con lo anterior, se han establecido las siguientes asignaciones presupuestales: 
- Para incrementar el número de Investigadores altamente calificados, se están programando en los planes, en los próximos tres años, $\$ 3.000 .000 .000$.00.

- Para intensificar el número de docentes cualificados, la suma de \$2.028.000.000.oo.

- Para financiar un mayor número de proyectos de investigación, la suma de \$2.400.000.000.oo.

Todo esto ha hecho que, en los últimos años, la U.D.C.A se haya concentrado en fortalecer la oferta académica de posgrados, tanto en el ámbito de Especializaciones como de Maestrías, hasta tal punto, que se está analizando y estudiando la posibilidad de consolidar su primer Doctorado en Ciencias Agropecuarias, lo que constituye una opción para la sociedad colombiana, de contar con niveles de formación de alta calidad, en disciplinas no convencionales, favoreciendo la democratización e inclusión.

Nuestra comunidad universitaria demuestra un alto sentido de pertenencia y de bienestar, lo que conlleva que las iniciativas encaminadas para este efecto, han dado resultado y, por ello, contamos con generaciones de nuevos egresados, que saben que los profesionales de la U.D.C.A son altamente competitivos, lo que nos invita a responder a este reconocimiento, con programas y acciones muy sólidas y que aportan al desarrollo contemporáneo Colombiano. 